\title{
The immunosuppressive effect of gossypol in mice is mediated by inhibition of lymphocyte proliferation and by induction of cell apoptosis
}

\author{
Wen-bin $\mathrm{XU}^{1}$, Li-hui $\mathrm{XU}^{2}$, Hong-song $\mathrm{LU}^{1}$, Dong-yun OU-YANG ${ }^{1}$, Huan-jing $\mathrm{SHI}^{1}$, Jing-fang $\mathrm{DI}^{1}$, Xian-hui $\mathrm{HE}^{1, *}$ \\ ${ }^{1}$ Institute of Tissue Transplantation and Immunology; ${ }^{2}$ Institute of Bioengineering, College of Life Science and Technology, Ji-nan University, Guangzhou \\ 510632, China
}

\begin{abstract}
Aim: To investigate the immunosuppressive effect of gossypol in mice both in vitro and in vivo.
Methods: The in vitro effect of gossypol on the proliferation of lymphocytes isolated from lymph nodes of BALB/c mice was determined by CFSE staining and by an MTS assay. Lymphocyte activation and lymphoblastic transformation were evaluated with immunostaining. Cell apoptosis was detected by Annexin-V and Hoechst 33342 staining. The in vivo immunosuppressive effect of gossypol on the DTH reaction was evaluated using a mouse DTH model induced by 2,4-dinitro-1fluorobenzene (DNFB). The thickness of the ears was measured, and the histological changes of the mouse auricles were observed after hematoxylin-eosin staining. The proliferation capacity of lymphocytes from DTH mice was also assayed. Results: In vitro, gossypol could significantly inhibit the proliferation of mouse lymphocytes stimulated with phorbol ester plus ionomycin in a dose-dependent manner. Although the expression of the early activation antigen CD69 was not affected, the lymphoblastic transformation of both $\mathrm{T}$ and B lymphocyte subsets was significantly suppressed by gossypol. Moreover, gossypol could induce apoptosis of lymphocytes, and the effect was time- and dose-dependent. In vivo, the DTH reaction in mice was markedly alleviated by gossypol injected intraperitoneally. Lymphocytes from drug-treated DTH mice had a reduced proliferation capacity as compared with lymphocytes from untreated DTH mice. Gossypol treatment also markedly reduced the number of infiltrated lymphocytes in the auricles of DTH mice.

Conclusion: Gossypol exhibited immunosuppressive effects in mice, probably by inhibition of lymphocyte proliferation and by induction of cell apoptosis.
\end{abstract}

Keywords: gossypol; lymphocytes; cell proliferation; apoptosis; delayed-type hypersensitivity

Acta Pharmacologica Sinica (2009) 30: 597-604; doi: 10.1038/aps.2009.35; published online 13th April 2009

\section{Introduction}

Gossypol, a yellow polyphenolic compound originally extracted from cottonseed, possesses antifertility activity and has been used as a male contraceptive drug for many years ${ }^{[1]}$. In recent years, gossypol has also been reported to exhibit a variety of other biological activities, including antitumor, anti-bacterial, anti-oxidant, and anti-inflammatory activities, as well as antiviral activity against a number of enveloped viruses such as the human immunodeficiency virus $(\mathrm{HIV})^{[2,3]}$. It has also been found to be a protein kinase $\mathrm{C}$ (PKC) inhibitor, and it suppresses the $\mathrm{T}$ cell activation in

* Correspondence to Dr Xian-Hui HE.

E-mail thexh@jnu.edu.cn

Received 2008-12-03 Accepted 2009-02-18 vitro normally seen in response to polyclonal activators ${ }^{[4]}$. As expression of NF- $\mathrm{kB}$-regulated genes plays important roles in oncogenesis and inflammatory responses ${ }^{[5,6]}$, gossypol is presumed to exhibit anti-tumor activity through the suppression of NF-kB activity and NF- $\mathrm{kB}-$ related gene expression ${ }^{[7]}$. Considering the previously reported anti-inflammatory activity of gossypol ${ }^{[8,9]}$, this reagent has been suggested to be a potential drug for the treatment of psoriasis ${ }^{[10]}$. Further investigation of the effects of gossypol on lymphocytes is still required to better understand its targets at the cellular and molecular levels. The aim of this study is to investigate the immunosuppressive effects of gossypol both in vitro and in vivo in mice. Our results indicate that gossypol exhibited an immunosuppressive effect in mice, probably by inhibition of lymphocyte proliferation and by induction of cell apoptosis. 


\section{Materials and methods}

Animals and reagents Female BALB/c mice, 6-8 weeks of age, were supplied by the Experimental Animal Center of Southern Medical University (Guangzhou, China). Gossypol (98\% purity), Hoechst 33342, phorbol 12,13-dibutyrate (PDB), ionomycin (Ion) and dimethyl sulfoxide (DMSO) were purchased from Sigma (USA). RMPI-1640 and fetal bovine serum (FBS) were obtained from GibcoBRL (USA). Carboxyfluorescein diacetate succinimidyl ester (CFSE) was a product of Molecular Probes (USA). 2,4-Dinitro-1fluorobenzene (DNFB) was obtained from Kasei Kogyo (Japan). A CellTiter96 Aqueous One Solution Cell Proliferation Assay kit (MTS) was purchased from Promega (USA). Phycoerythrin (PE)-conjugated Annexin V (Annexin V-PE) and 7-amino-actinomycin $\mathrm{D}$ (7-ADD) were obtained from Becton Dickinson (USA). Fluorescent labeled monoclonal antibodies against CD4 (FITC), CD8 (APC), CD19 (PerCP-Cy5.5), and CD69 (PE) were purchased from eBioscience (USA).

Isolation of lymphocytes and cell culture $\mathrm{BALB} / \mathrm{c}$ mice were sacrificed and the lymph nodes were isolated (2-3 mice were sacrificed in each experiment). A single-cell suspension was prepared by passing the tissue through a 200- $\mu \mathrm{m}$ nylon mesh screen. The cells were washed twice with PBS, counted and resuspended in RPMI-1640 medium containing $10 \%$ FBS (complete medium). Lymphocytes at a density of $2 \times 10^{6} / \mathrm{mL}$ were added to a 96 -well plate $(200 \mu \mathrm{L} /$ well $)$ and incubated at $37^{\circ} \mathrm{C}$ in a humidified atmosphere of $5 \% \mathrm{CO}_{2}$. Cells were stimulated with PDB $\left(1 \times 10^{-7} \mathrm{~mol} / \mathrm{L}\right)$ plus Ion $(0.5 \mu \mathrm{g} / \mathrm{mL})$ in the presence or absence of different concentrations of gossypol. Gossypol was dissolved in DMSO (the final concentration of DMSO was less than $0.025 \%$ ).

Flow cytometry analysis The lymphocytes were collected after $24 \mathrm{~h}$ of PDB plus Ion stimulation and were labeled with fluorescent antibodies against CD4, CD8, $\mathrm{CD} 19$, and $\mathrm{CD} 69$ at $4{ }^{\circ} \mathrm{C}$ for $20 \mathrm{~min}$. The cells were then washed with PBS, fixed with $4 \%$ paraformaldehyde in PBS, and analyzed on a FACSCalibur flow cytometer (Becton Dickinson, USA).

CFSE labeling assay CFSE-labeling was performed as described previously ${ }^{[11]}$. Briefly, lymphocytes at $2 \times 10^{7}$ cells $/ \mathrm{mL}$ were stained with CFSE $(2 \mu \mathrm{mol} / \mathrm{L})$ for $10 \mathrm{~min}$ at $37^{\circ} \mathrm{C}$, washed twice with PBS, and resuspended in RPMI1640 medium containing $10 \%$ FBS. Lymphocytes at $2 \times 10^{6}$ cells $/ \mathrm{mL}$ were seeded in a 24 -well plate $(500 \mu \mathrm{L} /$ well $)$ and harvested after $48 \mathrm{~h}$ of incubation. The fluorescence intensity of the lymphocytes was analyzed on a FACSCalibur flow cytometer.

MTS assay Lymphocytes in 96-well plates were treated with various concentrations of gossypol and then cultured for $48 \mathrm{~h}$ at $37^{\circ} \mathrm{C}$ in a $5 \% \mathrm{CO}_{2}$ incubator. Twenty microliters of the MTS solution was added to each well, and the plates were incubated for another $4 \mathrm{~h}$. The absorbance at $490 \mathrm{~nm}$ was measured using a microplate reader (Bio-Rad, USA).

Apoptosis analysis After incubation with gossypol for 8-48 h, lymphocytes were harvested and washed twice with cold PBS. The cells were resuspended in $100 \mu \mathrm{L}$ of binding buffer and incubated with $5 \mu \mathrm{L}$ of Annexin V-PE and $5 \mu \mathrm{L}$ of 7-AAD in the dark for $15 \mathrm{~min}$. Finally, $400 \mu \mathrm{L}$ of binding buffer was added to each tube, and the cells were analyzed by a flow cytometer.

Nuclear morphology Lymphocytes were seeded in 24-well plates and treated with different concentrations of gossypol for $24 \mathrm{~h}$. After washing twice with PBS, the cells were stained with Hoechst 33342 solution (final concentration $2.5 \mu \mathrm{g} / \mathrm{mL}$ ) and then incubated at $37^{\circ} \mathrm{C}$ for $30 \mathrm{~min}$, spun at $1500 \mathrm{r} / \mathrm{min}$ for $5 \mathrm{~min}$, and transferred to a slide covered with a cover slip. The nuclear morphology was observed under a confocal microscope (Perkin Elmer, USA) using ultraviolet light. The percentage of apoptotic cells was calculated from ten randomly selected microscopic fields (400×magnification).

Delayed-type hypersensitivity (DTH) A DTH assay was performed as previously described ${ }^{[12,13]}$. Five BALB/c mice in each group were sensitized by applying $20 \mu \mathrm{L}$ of $0.5 \%$ DNFB dissolved in a mixture of acetone and olive oil (4:1) on the shaved abdomen. Five days after the initial sensitization, the animals were challenged with $10 \mu \mathrm{L}$ of $0.2 \%$ DNFB on the left ear. The right ear of each mouse was treated with acetone-olive oil vehicle. Gossypol $\left(25 \mathrm{mg} \cdot \mathrm{kg}^{-1} \cdot \mathrm{d}^{-1}\right)$ was administered (ip) for 7 consecutive days from the day of sensitization. The thickness of the ears was measured with an engineer's micrometer at $48 \mathrm{~h}$ after challenge. The mice were then sacrificed and the thymuses and spleens were dissected out. The weight of the organs was recorded. The proliferation ability of the lymphocytes isolated from the lymph nodes of five mice in each group was analyzed by an MTS assay after stimulation with PBD plus Ion for $48 \mathrm{~h}$. The auricles were fixed in $10 \%$ phosphate-buffered formalin and embedded in paraffin wax. Sections of $5 \mu \mathrm{m}$ were stained with hematoxylin-eosin and observed under a microscope.

Statistical analysis Data are expressed as mean \pm SD. Statistical analysis was performed using the unpaired Student's $t$-test. $P<0.05$ was considered statistically significant. 


\section{Results}

Inhibition of in vitro lymphocyte proliferation by gossypol Initially, we examined the effect of gossypol on the proliferation of lymphocytes in response to polyclonal activators using a CFSE-staining assay. The fluorescence intensity of CFSE-labeled cells decreased by one half after each cell division. Thus, the cell proliferation (or division) rate can be analyzed by flow cytometry. As shown in Figure 1A, no cell proliferation was observed in the control group without activators, whereas more than $50 \%$ of the lymphocytes underwent cell division at least once when they were stimulated with PDB plus ionomycin (Ion) for $48 \mathrm{~h}$. Gossypol ( 8 $\mu \mathrm{mol} / \mathrm{L}$ or higher) could significantly inhibit cell division and the proliferation rate of the lymphocytes activated by PDB plus Ion in a dose-dependent manner. Meanwhile, an MTS assay was performed to confirm the effect of gossypol. This assay also showed that gossypol inhibited lymphocyte proliferation in a dose-dependent manner (Figure 1B).

Gossypol suppressed lymphoblastic transformation Next, flow cytometry was used to analyze whether gossypol had a selective effect on the activation and lymphoblastic transformation of $\mathrm{T}$ and $\mathrm{B}$ lymphocyte subsets. As shown in Figure 2, gossypol at concentrations of $8 \mu \mathrm{mol} / \mathrm{L}$ and $16 \mu \mathrm{mol} / \mathrm{L}$ had no significant effect on the expression of the early activation antigen CD69 (the cells in the upper quadrants) on CD4 T cells, CD8 T cells, or CD19 B cells, suggesting that at these two doses gossypol did not inhibit lymphocyte activation. However, the lymphoblastic transformation [the sizes of lymphocytes were proportional to values of the forward scatter (FSC)] of CD4 T cells, CD8 T cells, and CD19 B cells was markedly inhibited by $16 \mu \mathrm{mol} / \mathrm{L}$ of gossypol when compared with the lymphoblastic transformation of the lymphocytes treated only with PDB plus Ion (10\%-20\% vs $70 \%-80 \%$ in the upper right quadrants). Meanwhile, the aggregated colony sizes of gossypol-treated lymphocytes were also significantly smaller than the aggregated colony sizes of cells in the PDB plus Ion group (Figure S1). As the lymphoblastic transformation and aggregated colony formation were positively correlated with subsequent cell proliferation, this result suggests that gossypol could inhibit proliferation of both $\mathrm{T}$ and $\mathrm{B}$ lymphocytes without any selective effect on the lymphocyte subsets.

Gossypol induced apoptosis in lymphocytes We examined whether gossypol inhibited lymphocyte function by induction of cell apoptosis. Apoptotic cells were identified by Annexin V-PE positive/7-AAD negative staining. As shown in Figure 3A, gossypol could induce apoptosis in lymphocytes activated with PDB plus Ion as early as $8 \mathrm{~h}$ after the start of the incubation, and this effect was dose-dependent.
A

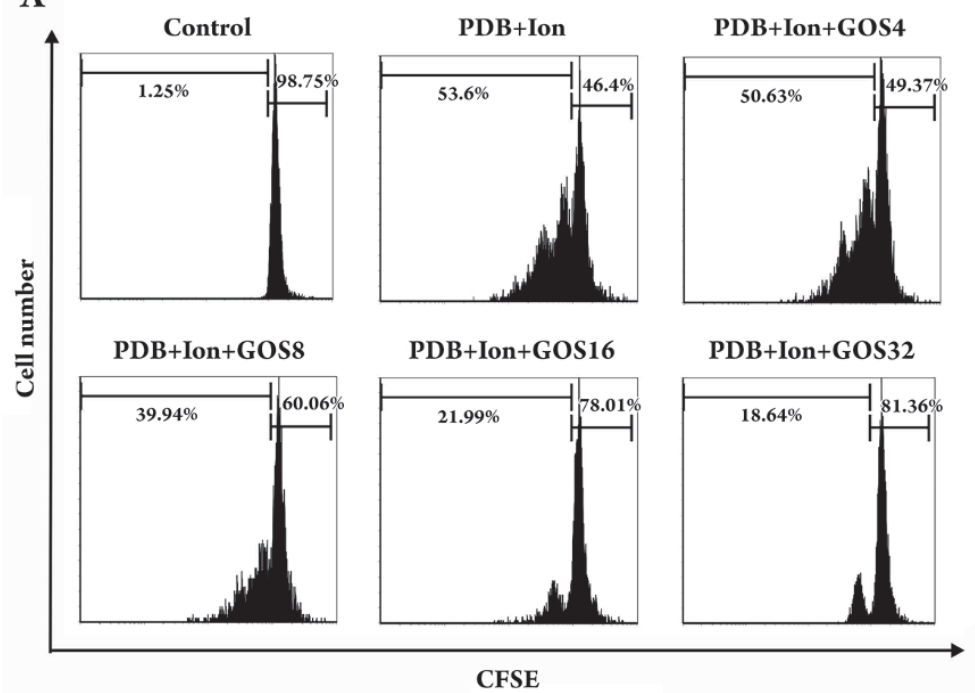

B

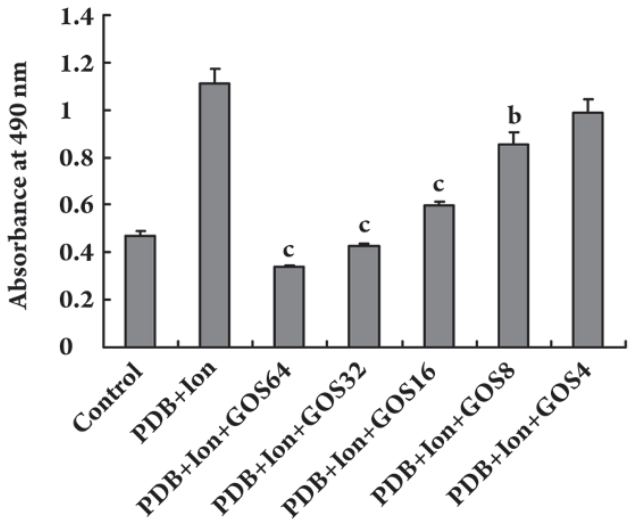

Figure 1. Inhibitory effect of gossypol on the proliferation of mouse lymphocytes. (A) Flow cytometry analysis of CFSE-labeled cells. Lymphocytes were stained with CFSE and stimulated with PDB+Ion for $48 \mathrm{~h}$ in the presence of various concentrations of gossypol. (B) MTS assay. Cells were stimulated with PDB+Ion for $48 \mathrm{~h}$ in the presence of various concentrations of gossypol. At the end of the culturing period, $20 \mu \mathrm{L}$ of the MTS solution was added to each well, and then the cells were incubated for another $4 \mathrm{~h}$. The absorbance at $490 \mathrm{~nm}$ was measured using a microplate reader. Values are expressed as the mean \pm SD. ${ }^{b} P<0.05,{ }^{c} P<0.01 v s$ PDB+Ion group. GOS: gossypol; GOS64: $64 \mu \mathrm{mol} / \mathrm{L}$ GOS; GOS32: $32 \mu \mathrm{mol} / \mathrm{L}$ GOS; GOS16: $16 \mu \mathrm{mol} / \mathrm{L}$ GOS; GOS8: $8 \mu \mathrm{mol} / \mathrm{L}$ GOS; GOS4: $4 \mu \mathrm{mol} / \mathrm{L}$ GOS. 

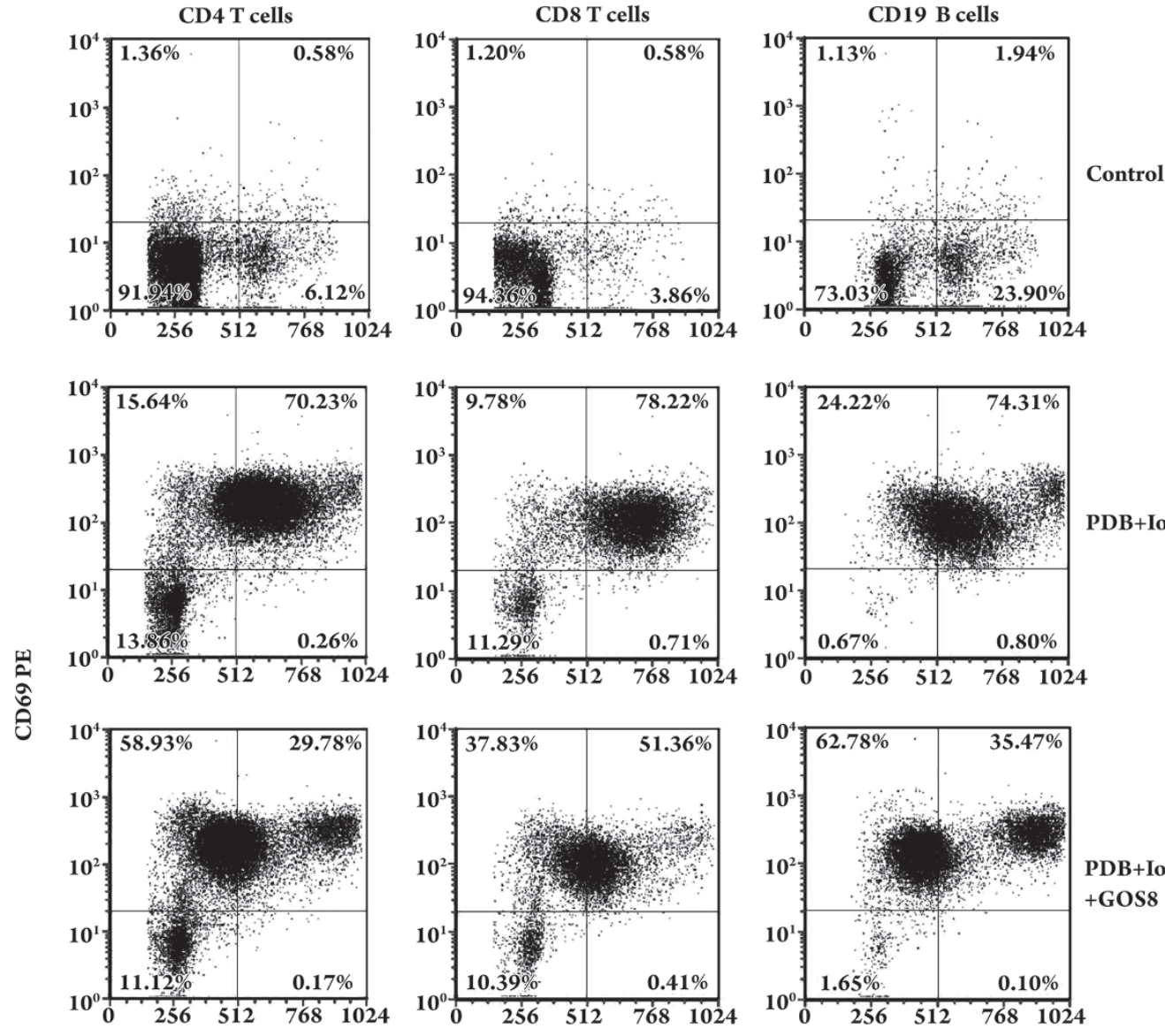

PDB+Ion
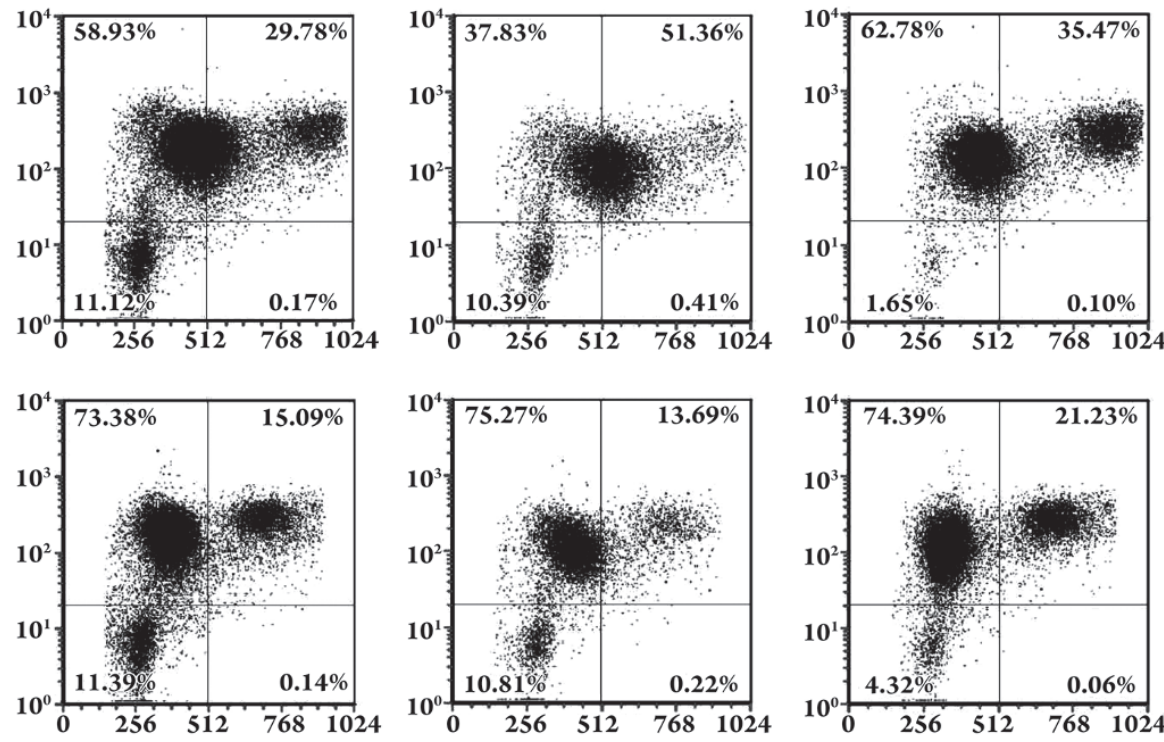

PDB+Ion +GOS8
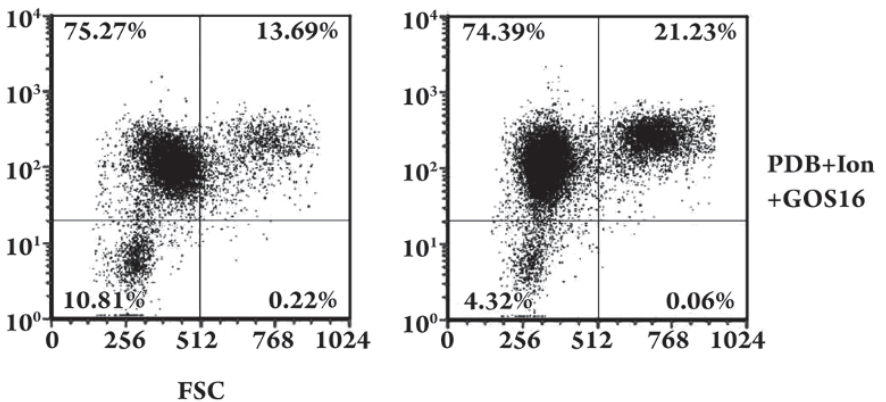

Figure 2. Flow cytometry analysis of the effect of gossypol on CD69 expression and on lymphoblastic transformation of lymphocytes stimulated by PDB plus Ion for $24 \mathrm{~h}$. One representative dot plot of each triplicate is presented. GOS: gossypol; GOS16: $16 \mu \mathrm{mol} / \mathrm{L}$ GOS; GOS8: $8 \mu \mathrm{mol} / \mathrm{L}$ GOS.

The apoptotic proportions of lymphocytes treated with 8,16 , and $32 \mu \mathrm{mol} / \mathrm{L}$ of gossypol were $4.39 \%, 6.57 \%$, and $12.14 \%$, respectively, and the PDB plus Ion control value was $2.13 \%$. The proportion of apoptotic cells increased as the incubation time increased, suggesting that the effect of gossypol was also time-dependent (Figure 3B).

Hoechst 33342 staining can reveal apoptotic cells with fragmented or condensed nuclei. As shown in Figure 4, the nuclei of the control lymphocytes were uniformly blue, whereas some nuclei of the gossypol-treated cells contained small bright blue dots representing nuclear fragmentation and/or chromatin condensation, the typical characteristics of apoptotic nuclei. When treated with $16 \mu \mathrm{mol} / \mathrm{L}$ of gossypol for $24 \mathrm{~h}$, the activated lymphocytes had a significantly higher proportion of apoptotic nuclei as compared with the resting lymphocytes $[(16.5 \pm 2.1) \%$ vs $(10.3 \pm 1.9) \%$; the per- 

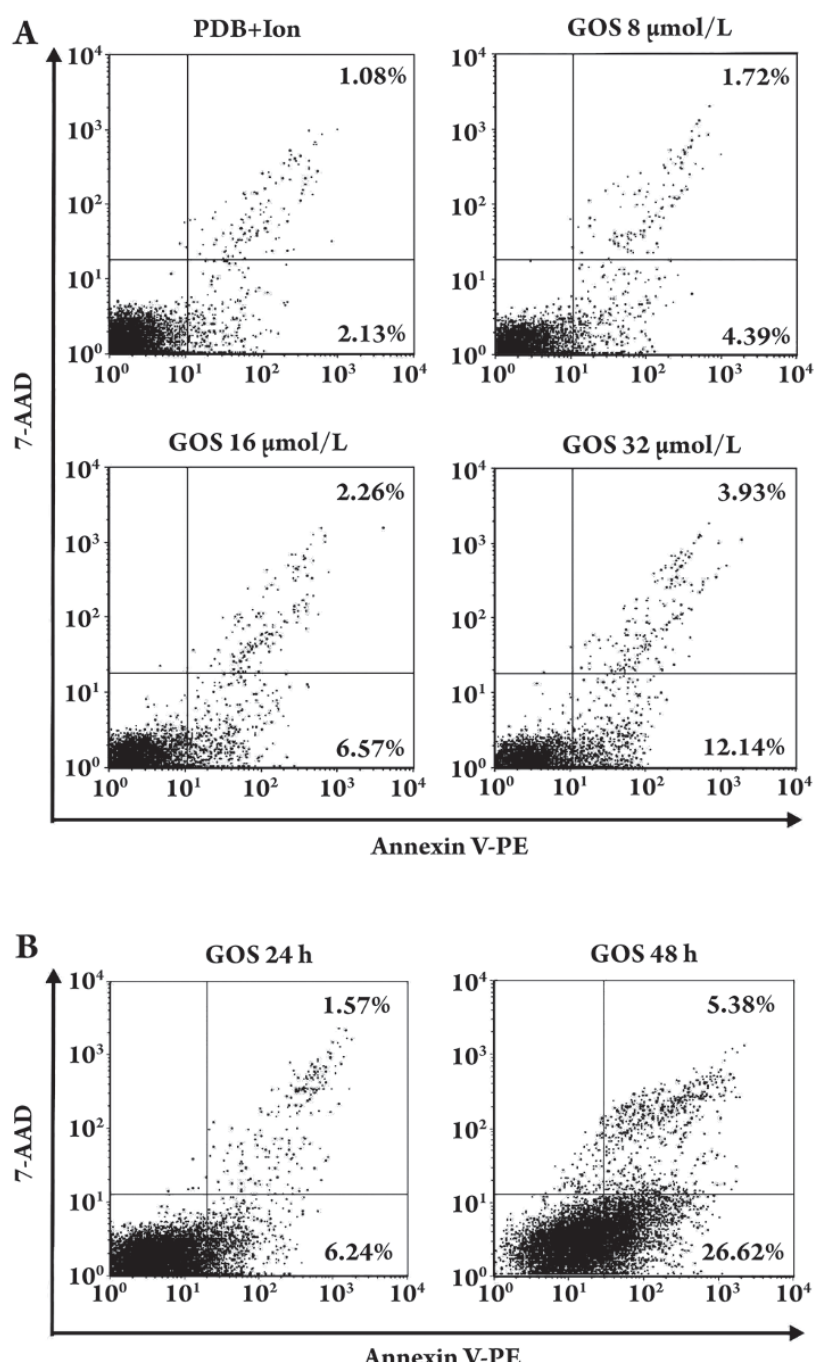

Annexin V-PE

Figure 3. Flow cytometry analysis of apoptosis in mouse lymphocytes using Annexin-V staining. (A) Cells were stimulated with PDB+Ion for $8 \mathrm{~h}$ in the presence of various concentrations of gossypol. (B) Cells were stimulated with PDB+Ion for 24 and $48 \mathrm{~h}$ in the presence of $8 \mu \mathrm{mol} / \mathrm{L}$ gossypol. Values are the ratios of the percentage of cells in early apoptosis (Annexin V-PE positive/7-AAD negative) to the percentage of cells in late apoptosis (Annexin V-PE positive/7$\mathrm{AAD}$ positive). One representative experiment of three independent experiments is presented.

centage of apoptotic cells was calculated from ten random microscope fields at $400 \times$ magnification] $(P<0.05)$.

Effect of gossypol on the DTH reaction In the DTH mouse model, DNFB induced a pronounced inflammatory reaction in the challenged ears as compared with the control ears. When treated with gossypol, ear swelling was markedly reduced, whereas the body weight was not affected (Table $1)$. Meanwhile, the thymus and spleen indexes of the gossypol-treated group also decreased $(P<0.05)$ (Table 2$)$. In
Table 1. Comparison of ear thickness and body weight of mice in different groups. Mean \pm SD. $n=5$. ${ }^{\mathrm{b}} \mathrm{P}<0.05$ vs DTH group.

\begin{tabular}{|c|c|c|c|}
\hline \multirow{2}{*}{ Group } & \multicolumn{2}{|c|}{ Body weight (g) } & \multirow{2}{*}{$\begin{array}{c}\text { Difference in ear } \\
\text { thickness } \\
\text { (left ear-right ear) } \\
(\mathrm{mm})\end{array}$} \\
\hline & 1 day & 8 day & \\
\hline Control & $16.65 \pm 0.79$ & $17.68 \pm 0.76$ & $0.02 \pm 0.02$ \\
\hline DTH & $15.53 \pm 1.77$ & $16.46 \pm 1.25$ & $0.28 \pm 0.04$ \\
\hline GOS-treated & $17.33 \pm 1.63$ & $16.0 \pm 1.21$ & $0.13 \pm 0.03^{\mathrm{b}}$ \\
\hline
\end{tabular}

Table 2. Comparison of thymus indexes and spleen indexes for different groups. The indexes of the thymus and spleen were calculated as the ratio of organ weight $(\mathrm{mg})$ to total body weight $(\mathrm{g})$. Mean \pm SD. $n=5 .{ }^{\mathrm{b}} P<0.05$ vs control group.

\begin{tabular}{lcc}
\hline Group & Thymus index & Spleen index \\
\hline Control & $2.14 \pm 0.6$ & $3.5 \pm 0.7$ \\
DTH & $2.81 \pm 0.5$ & $4.23 \pm 0.9$ \\
GOS-treated & $1.45 \pm 0.3^{\mathrm{b}}$ & $2.35 \pm 0.6^{\mathrm{b}}$
\end{tabular}

addition, the MTS results showed that the proliferation rate of the lymphocytes from the gossypol-treated group was significantly lower than the proliferation rate in the DTH group without any treatment $(P<0.05)$ (Figure 5). These results suggest that gossypol exhibited an in vivo immunosuppressive effect in mice, probably through inhibiting lymphocyte proliferation.

Histological analysis of auricle tissue from DTH mice Histological sections of auricle tissue showed that the DNFB-challenged ears of DTH mice suffered from edema and had been infiltrated with a large number of inflammatory cells. The gossypol treatment reduced ear edema and leukocyte infiltration (Figure 6). This was consistent with the measurement of ear thickness (Table 1). Together, these results suggest that gossypol could significantly inhibit the DNFB-induced DTH reaction.

\section{Discussion}

In the present study, we used both lymphocytes cultured in vitro and an in vivo DTH mouse model to evaluate the immunosuppressive effect of gossypol. In the in vitro assays, we showed that gossypol inhibited the proliferation of mouse lymphocytes stimulated with polyclonal activators in a doseand time-dependent manner and that gossypol could also induce cell apoptosis in both resting and activated lymphocytes. It appeared that the inhibitory activity of gossypol 

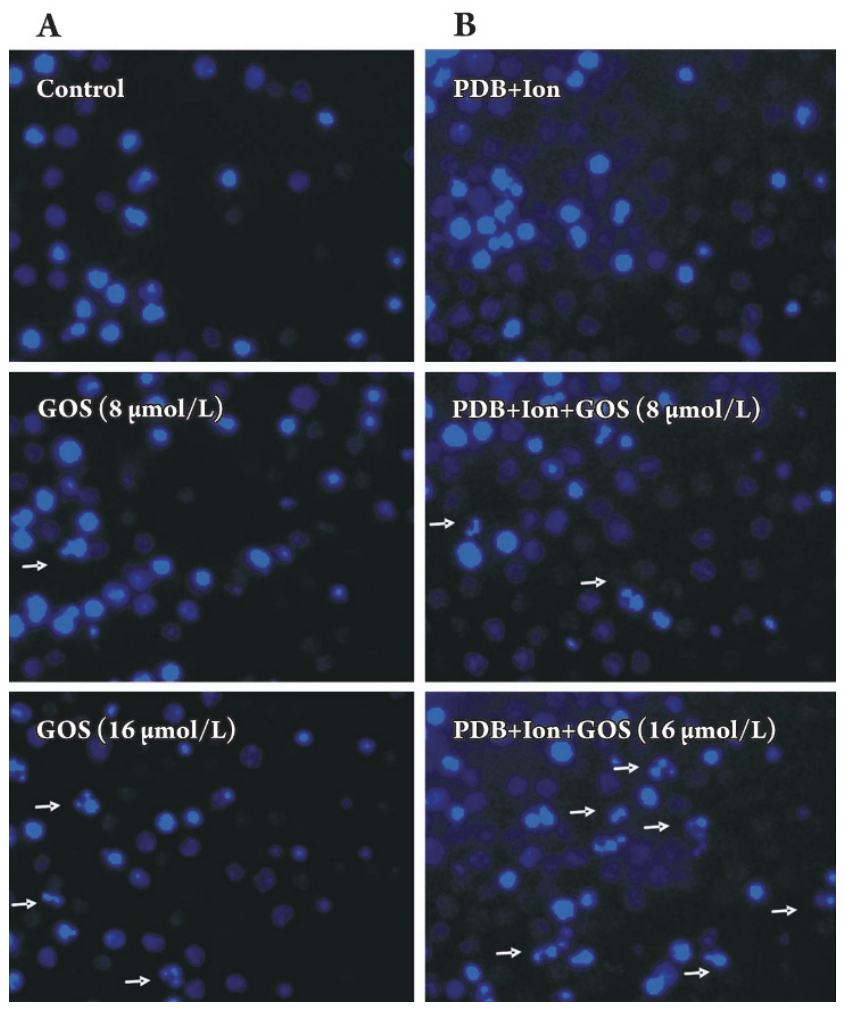

Figure 4. The nuclear morphology of mouse lymphocytes stained with Hoechst 33342 (400xmagnification). (A) Resting lymphocytes treated with gossypol for $24 \mathrm{~h}$. (B) PDB+Ion-activated lymphocytes treated with gossypol for $24 \mathrm{~h}$. Arrows show the apoptotic cells. GOS: gossypol.

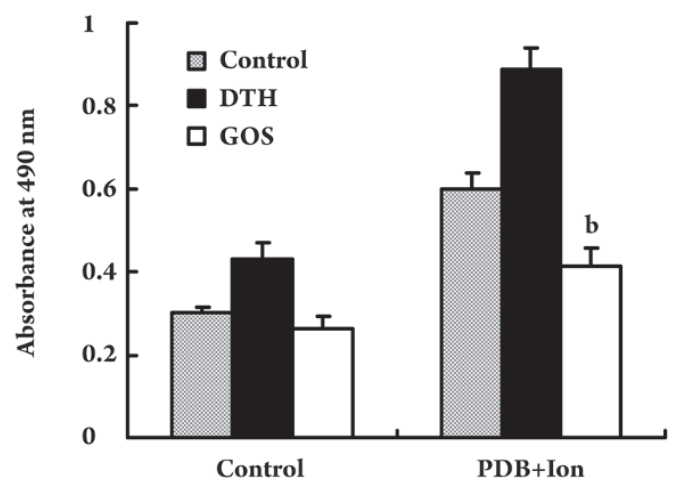

Figure 5. Inhibitory effect of gossypol on the proliferation of lymphocytes from DTH model mice. Gossypol $\left(25 \mathrm{mg} \cdot \mathrm{kg}^{-1} \cdot \mathrm{d}^{-1}\right)$ was administered for 7 days by ip injection before the mice were sacrificed. Lymphocytes were isolated from lymph nodes and were stimulated with PDB plus Ion and then cultured for $48 \mathrm{~h}$ at $37^{\circ} \mathrm{C}$ in a humidified atmosphere of $5 \% \mathrm{CO}_{2}$. At the end of the culturing period, $20 \mu \mathrm{L}$ of MTS solution was added to each well, and then the cells were incubated for another $4 \mathrm{~h}$. The absorbance at $490 \mathrm{~nm}$ was measured using a microplate reader. Data are presented as the mean \pm SD. $n=6$. ${ }^{\mathrm{b}} P<0.05$ vs DTH group. GOS: gossypol.

was not confined to one of the lymphocyte subsets as the lymphoblastic transformation of all lymphocyte subsets was suppressed, although the expression of the early activation marker CD69 was not blocked by this reagent. Moreover, the in vivo study using the DTH model revealed that gossypol could suppress inflammatory ear edema and infiltration
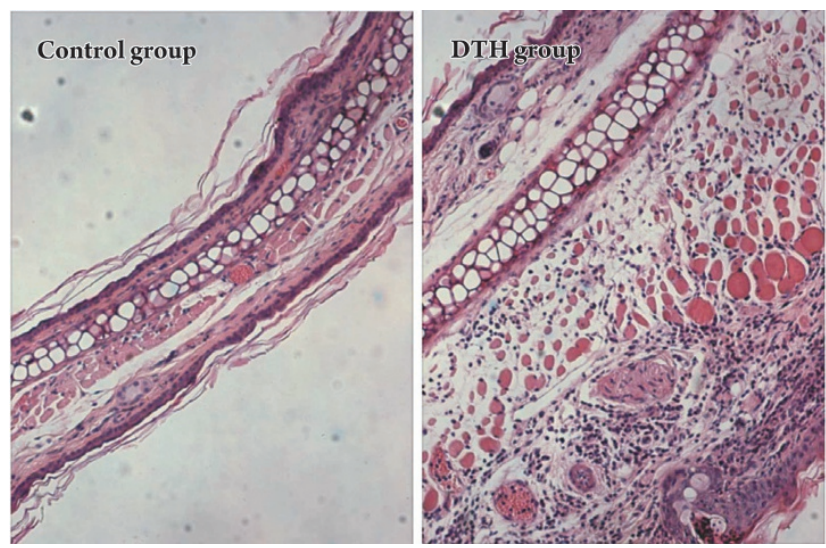

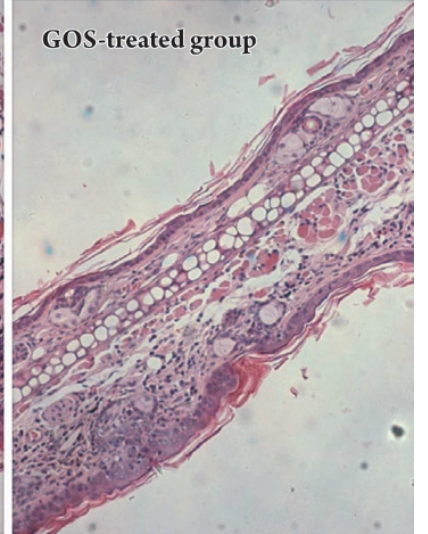

Figure 6. Hematoxylin-eosin staining of mouse auricle tissue sections $(\times 100)$. See Material and Methods for details. GOS: gossypol.
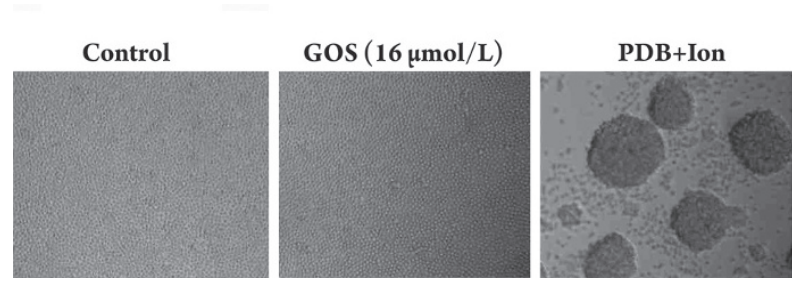

PDB+Ion + GOS $8 \mu \mathrm{mol} / \mathrm{L}$

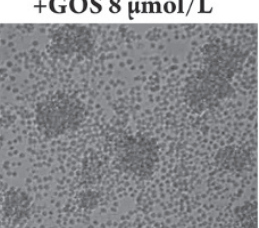

PDB+Ion + GOS $16 \mu \mathrm{mol} / \mathrm{L}$ 
of lymphocytes in the DNFB-treated ears. The target on which gossypol exerted its effect might exist in lymphocytes because the lymphocytes from gossypol-treated mice had a reduced proliferation capacity as compared with lymphocytes from control mice. Taken together, our data suggest that gossypol exhibits an immunosuppressive effect on mice, probably by inhibiting proliferation and inducing apoptosis of lymphocytes.

The exact target of gossypol in lymphocytes is still unknown. It has been reported that gossypol is an inhibitor of protein kinase $\mathrm{C}(\mathrm{PKC})^{[14]}$, which has been shown to markedly reduce the expression of interleukin- 2 and interferon- $\gamma$ in activated human $T$ lymphocytes in response to polyclonal activators ${ }^{[15]}$. Pharmacologic activators of PKC, such as PDB, which enters the cells and directly activates PKC, and calcium ionophores, such as ionomycin, which raises the cytosolic free calcium ion concentration, can act together to stimulate lymphocyte activation, interleukin-2 synthesis and lymphocyte proliferation. Consistent with a previous study on human lymphocytes ${ }^{[15]}$, the current research also showed that gossypol significantly inhibited the proliferation of mouse lymphocytes in response to PDB plus ionomycin. It seems that gossypol may inhibit lymphocyte proliferation by blocking PKC activity and the calcium signaling pathway. However, the expression of CD69, an early activation marker of lymphocytes that is upregulated by PKC activation ${ }^{[16]}$, was not affected at the doses of gossypol used in this study. We presume that gossypol might act on multiple targets besides PKC or that low concentrations of gossypol might not effectively block PKC activity and CD69 expression induced by PDB, while it could still act on the other components of the signaling pathway, such as calcium signaling, thereby inhibiting lymphocytic transformation and proliferation. Other potential action sites of gossypol remain to be identified in lymphocytes.

Over the past several decades, gossypol has been demonstrated to induce apoptosis in several tumor cell lines in vitro and has been suggested to be a potential anti-tumor drug $^{[17-19]}$. The mechanism of gossypol's anti-tumor activity may involve cell cycle arrest in the $G_{0} / G_{1}$ phase by upregulating p51 and $\mathrm{p} 21^{[20-22]}$. Recent studies have also shown that gossypol-induced apoptosis is followed by a caspasedependent and -independent processes that involves the release of AIF from the mitochondria to the cytosol, a process that is the result of inhibiting the heterodimerization of $\mathrm{Bcl}-\mathrm{X}_{\mathrm{L}} / \mathrm{Bcl}-2$ with pro-apoptosis molecules ${ }^{[23-25]}$. Gossypol also induces the truncation of the Bid protein, the loss of mitochondrial membrane potential $\left(\Delta \Psi_{\mathrm{m}}\right)$, the release of cytochrome $\mathrm{c}$ from mitochondria into the cytosol, and the activation of caspases 3,8 , and $9^{[26]}$. In the present study, we showed that gossypol could induce the apoptosis of mouse lymphocytes in a time- and dose-dependent manner, but higher concentrations of gossypol may cause largely necrotic cell death (data not shown). Our results are in accordance with a previous study in which the concentrations of gossypol required to induce apoptosis of human lymphocytes without causing necrosis were between 25 and $50 \mu \mathrm{mol} / \mathrm{L}^{[27]}$. The doses of gossypol we used to induce lymphocyte apoptosis were lower than $25 \mu \mathrm{mol} / \mathrm{L}$ and caused only a minor proportion of necrosis. Further studies are warranted to determine whether gossypol induces apoptosis in mouse lymphocytes by a similar mechanism as it does in tumor cells, in which gossypol binds to and inhibits $\mathrm{Bcl}-\mathrm{X}_{\mathrm{L}}$ and $\mathrm{Bcl}-2^{[24,25]}$.

Gossypol is suggested to be a potential reagent for the treatment of psoriasis ${ }^{[10]}$, as it has been found that gossypol possesses anti-proliferative activity against keratinocytes at doses that are non-toxic to humans ${ }^{[28]}$ and that lack mutagenicity ${ }^{[29]}$. Psoriasis is a common chronic inflammatory skin disease characterized by a marked inflammatory infiltrate and by the hyperproliferation of keratinocytes. $\mathrm{T}$ lymphocytes play a crucial role in the immunopathogenesis of this disease ${ }^{[30]}$. In the present study, our data suggest that gossypol might suppress the mouse DTH reaction by reducing the proliferation and infiltration of lymphocytes. Thus our data also imply that gossypol may exhibit an effect beneficial for the treatment of psoriasis. As systemic injection of gossypol markedly decreased the thymus and spleen indexes, which suggested that this reagent has potential in vivo toxicity to the immune organs at the doses we used in this study. Local administration at the site of the lesions, such as those caused by psoriasis, may be the preferred approach for the treatment of some inflammatory diseases. Other routes, such as oral administration, are also worth testing for gossypol treatment.

In summary, our results suggest that gossypol not only could inhibit the proliferation of mouse lymphocytes and induce apoptosis in vitro but also could alleviate the DNFBinduced DTH reaction in vivo. These results suggest that gossypol may exert beneficial effects in the treatment of inflammatory diseases. Further investigation is warranted to identify the potential targets of gossypol's immunosuppressive effect.

\section{Acknowledgments}

This work was supported by the National Natural Science Foundation of China (№ 30572199, № 30230350, № 30371651) and the Key Subject of Biochemistry and 
Molecular Biology of Guangdong Province.

We thank Prof Qi-xuan XIE for her kind help in capturing images; Dr Xi-chao WANG for performing the flow cytometry analysis; Chun-yong LIU, Xiao-ying WANG, He GUO, Qi GAO, and Yu-ting LI for their excellent technical assistance; and Zhi YANG and Man-lin YAO for kindly helping with preparation of the manuscript.

\section{Author contribution}

Wen-bin XU and Xian-hui HE designed research; Wenbin XU, Li-hui XU, Hong-song LU, Huan-jing SHI, and Jingfang DI performed research; Wen-bin XU, Xian-hui HE, and Dong-yun OU-YANG analyzed data; Wen-bin XU, Xian-hui $\mathrm{HE}$, and Dong-yun OU-YANG wrote the paper.

\section{References}

1 Wu D. An overview of the clinical pharmacology and therapeutic potential of gossypol as a male contraceptive agent and in gynaecological disease. Drugs 1989; 38: 333-41.

2 Dodou K. Investigations on gossypol past and present developments. Expert Opin Investig Drugs 2005; 14: 1419-34.

3 Dao VT, Gaspard C, Mayer M, Georges HW, Suong NN, Rogert JM. Synthesis and cytotoxicity of gossypol related compounds. Eur J Med Chem 2000; 35: 805-13.

4 He XH, Zeng YZ, Li Z, Xu LH, Sun H, Zeng JM. Inhibitory effects of gossypol on the activation of human T-lymphocytes stimulated with polyclonal activators. Chin J Pathophysiol 2001; 17: 510-4.

5 Sharma HW, Narayanan R. The NF- $\kappa$ B transcription factor in oncogenesis. Anticancer Res 1996; 16: 589-96.

6 Albert S, Baldwin Jr. The NF- $\kappa B$ and IkB proteins: new discoveries and insights. Annu Rev Immunol 1996; 14: 649-83.

7 Moon DO, Kim MO, Lee JD, Kim GY. Gossypol suppresses NF$\kappa \mathrm{B}$ activity and NF- $\mathrm{\kappa B}$-related gene expression in human leukemia U937 cells. Cancer Lett 2008; 264: 192-200.

8 Benhaim P, Mathes SJ, Hunt TK, Scheuenstuh H, Benz CC. Induction of neutrophil Mac-1 integrin expression and superoxide production by the medicinal plant extract gossypol. Inflammation 1994; 18: 443-58.

9 Yu BZ, Rogers J, Ranadive G, Baker S, Wilton DC, Apitz CR, et al. Gossypol modification of Ala-1 of secreted phospholipase A2: a probe for the kinetic effects of sulfate glycoconjugates. Biochemistry 1997; 36: 12400-11.

10 Kalliopi D, Rosaleen JAW, John L, David APS, Michael DS, Paul WG. Synthesis of gossypol atropisomers and derivatives and evaluation of their anti-proliferative and anti-oxidant activity. Bioorg Med Chem 2005; 13: 4228-37.

11 Zhao JX, Zeng YY, He XH, Wang N, Di JF, Zeng S. Application of vital dye CFDA-SE to study lymphocytic proliferation. Chin J Cell Mol Immunol 2003; 19: 109-11.

12 Corsini AC, Bellucci SB, Costa MG. A simple method of evaluating delayed type hypersensitivity in mice. J Immunol Meth
1979; 30: 195-200.

13 Gad SC. The mouse ear swelling test (MEST) in the 1990. Toxicology 1994; 93: 33-46.

14 Nakadate T, Jeng AY, Blumberg PM. Comparison of protein kinase C functional assays to clarify mechanisms of inhibitor action. Biochem Pharmacol 1988; 37: 1541-5.

15 He XH, Zeng YY, Xu LH, Sun H, Li Z, Di JF. Influences of protein kinase $\mathrm{C}$ inhibitors on the expression of IL- 2 and IFN- $\gamma$ by human T-lymphocytes. Chin J Pathophysiol 2002; 18: 522-25.

16 Testi R, Phillips JH, Lanier LL. T cell activation via Leu-23 (CD69). J Immunol 1989; 143: 1123-8.

17 Tuszynski GP, Cossu G. Differential cytotoxicity of gossypol on human melonoma, colon carcinoma, and other tissue culture cell lines. Cancer Res 1984; 44: 768-71.

18 Gilbert NE, O'Reilly JE, Chang CJ, Lin YC, Brueggemeier RW. Antiproliferative activity of gossypol and gossypolone on human breast cancer cells. Life Sci 1995; 57: 61-7.

19 Wang XH, Wang J, Wong SC, Chow LS, Nicholls JM, Wong YC, et al. Cytotoxic effect of gossypol on colon carcinoma cells. Life Sci 2000; 67: 2663-71.

20 Thomas M, Von HV, Moustafa Y, Montmasson MP, Monet JD. Effects of gossypol on the cell cycle phases in T-47D human breast cancer cells. Anticancer Res 1991; 11: 1469-75.

21 Van PC, Seidman AD, Reidenberg MM, Moasser MM, Sklarin $\mathrm{N}$, Van ZK, et al. Oral gossypol in the treatment of patients with refractory metastatic breast cancer: a phase I/II clinical trial. Breast Cancer Res Treat 2001; 66: 239-48.

22 Ligueros M, Jeoung D, Tang B, Hochhauser D, Reidenberg MM, Sonenberg M. Gossypol inhibition of mitosis, cyclin D1 and Rb protein in human mammary cancer cells and cyclin-D1 transfected human fibrosarcoma cells. Br J Cancer 1997; 76: 21-8.

23 Zhang MC, Liu HP, Tian ZK, Griffith BN, Ji M, Li QT. Gossypol induces apoptosis in human PC-3 prostate cancer cells by modulating caspase-dependent and caspase-independent cell death pathways. Life Sci 2007; 80: 767-74.

24 Balakrishnan K, Wierda WG, Keating MJ, Gandhi V. Gossypol, a $\mathrm{BH} 3$ mimetic, induces apoptosis in chronic lymphocytic leukemia cells. Blood 2008; 112: 1971-80.

25 Meng Y, Tang W, Dai Y, Wu X, Liu M, Ji Q et al. Natural BH3 mimetic (-)-gossypol chemosensitizes human prostate cancer via Bcl- $\mathrm{x}_{\mathrm{L}}$ inhibition accompanied by increase of Puma and Noxa. Mol Cancer Ther 2008; 7: 2192-202.

26 Hou DX, Uto T, Tong XH, Takeshita T, Tanigawa S, Imamura $\mathrm{I}$, et al. Involvement of reactive oxygen species-independent mitochondrial pathway in gossypol-induced apoptosis. Arch Biochem Biophys 2004; 428: 179-87.

27 Yurtcu E, Ergun MA, Menevse A. Apoptotic effect of gossypol on human lymphocytes. Cell Biol Int 2003; 27: 791-94.

28 Coutinho EM. Gossypol: a contraceptive for men. Contraception 2002; 65: 259-63.

29 Li YF, Booth GM, Seegmiller RE. Evidence for embryotoxicity of gossypol in mice and chicks with no evidence of mutagenic activity in the ames test. Reprod Toxicol 1989; 3: 59-62.

30 Barker JN. Psoriasis as a T cell-mediated autoimmune disease. Hosp Med 1998; 59: 530-3. 